\title{
Guy Sebag, adieu mon ami
}

Peter J. Strouse

Published online: 28 December 2014

(C) Springer-Verlag Berlin Heidelberg 2014

Pediatric radiology lost a very dear friend and colleague Nov. 28 when Dr. Guy Sebag passed away suddenly and unexpectedly. I have had the enormous privilege of working with Guy for the last 2 years as co-editors of this journal, he in the European editorial office and I in the Americas editorial office.

Guy was an exceptional partner. He was dedicated and poured substantial time and energy into the journal. Guy was honest and open. He was a professional and extremely passionate for the work, always with our overarching goal of improving children's health care in mind. Guy had a very sharp intellect and an immense fund of knowledge. He was very skilled at bridging borders and working with colleagues from many countries and ethnicities. Guy was a visionary, not just focused on the relentless procession of papers through the journal office, but on learning more about cutting-edge topics and adapting the journal to new paradigms in order to better serve the pediatric radiology community. Guy was an integral contributor to the journal's success in countless ways.

Guy was a charming man. He was a true French gentleman and scholar. He was warm and fun. He had a wonderful sense of humor. Through pediatric radiology, he was a good friend to many throughout the world. He was cherished by his colleagues in Paris who worked with him on a daily basis.

Personally, I have lost a dear friend and collaborator. I have truly been blessed to work with Guy and will miss him immensely.

My thoughts and prayers are with Guy's wife, Christina Mouroutis, and with his three grown children, Alexandra, Paul and Angélique, whom he was very proud of. I wish them the best in a very sad and difficult time.

P. J. Strouse $(\square)$

Section of Pediatric Radiology,

C. S. Mott Children's Hospital, Room 3-231,

Department of Radiology,

University of Michigan Health System,

1540 E. Hospital Drive,

Ann Arbor, MI 48109-4252, USA

e-mail: Rad-Ped-Radiol-Journal@med.umich.edu 